\title{
The Relevance with Mental Health in the Activity Limitation and the Quality of Life in Korean Adults
}

\author{
Sang-Sub Park ${ }^{1 *}$ and Ju-Yeong An ${ }^{2}$ \\ 'Department of Emergency Medical Technology, Chung Cheong University, Korea; wooonseo@hanmail.net \\ ²Department of Emergency Medical Technology, Sungduk University, Korea
}

\begin{abstract}
The purpose of this study is to examine the relevance with mental health in the activity limitation and the quality of life in our country's adults. This study was based on the source data of "Korea Health Statistics 2012: Korea National Health and Nutrition Examination Survey [KNHANES V-3]" by Ministry of Health and Welfare (MW) and Korea Centers for Disease Control and Prevention (CDC). The subjects were composed of 5515 people excluding those aged under 20, missing values, and non-respondents from the primitive data. An analytical method of this study was made by using SPSS WIN 12.0 Version. As for the quality of life, the group having some problems with walking in terms of motor ability was about 1.4 times more likely to have depressive symptoms $(\mathrm{p}<.05)$. The group having problems with daily activity was about 2.4 times more likely to have depressive symptoms $(\mathrm{p}<.05)$. The group having moderate levels of psychological anxiety/depression (approx. 5 times, $\mathrm{p}<.001$ ) and the group having severe psychological anxiety/depression (approx. 14 times, $\mathrm{p}<.001$ ) were more likely to be depressed. In terms of the quality of life, activity limitation may cause a problem with daily living and mental health. It is necessary to develop programs and systems to solve this problem.
\end{abstract}

Keywords: Activity Limitation, Depression, Mental Health, Quality of Life

\section{Introduction}

Wade ${ }^{1}$ mentioned that the activity limitation gives a danger to self-preservation, causes conflict and aggression, leads to failing to feel pleasure of movement and to feeling a sense of frustration, reduces quantity and quality of sensory information, and drops interactive activity. Heo and $\mathrm{Cho}^{2}$ said that the activity limitation implies to have inconvenience in sight, hearing, speaking or behaving.

Lee and $\mathrm{Kim}^{3}$ mentioned that the quality of life needs to possess essential resource available for satisfying each individual's needs, wants, and desires. Also, it was said to be what an individual participates in activity available for being developed, behaves oneself, and is satisfied in comparison with other person.

$\mathrm{Heo}$ and $\mathrm{Cho}^{2}$ mentioned that a commonly significant element in health behavior is education level. Accordingly, to prevent the activity limitation and the deterioration, an interest in education was said to be necessarily concentrated for developing a health promotion program.

Hong et al. ${ }^{4}$ told that Chronic Obstructive Pulmonary Disease (COPD) is a disease with high prevalence and mortality and has influence upon the quality of life. The quality of life was said to be reduced in a COPD patient compared to an ordinary person and to be decreased more in the more serious airway obstruction. It was mentioned the need to carry out a multilateral approach and treatment such as improving a socio-economic factor and managing depression and comorbidity well in order to improve the quality of life in a COPD patient.

As for the factors contributing to the persistence or increase of depression, Park and Lee ${ }^{5}$ noted that women who were less educated and who had lost their spouse were more likely to suffer persistent depression. They also

* Author for correspondence 
indicated that women having financial problems could become depressed.

Lee et al. ${ }^{6}$ noted that people who were jobless and unreligious and were high school graduates were more likely to be depressed, regardless of gender, and that unmarried men in their twenties and married women in their fifties were more likely to be depressed.

Han et al. $^{7}$ noted that elderly people with physical disease were more likely to suffer depressive symptoms and disorders than normal ones and that dysfunction caused by physical diseases had the greatest impact on the depressive symptoms.

Depression may occur, regardless of age, and depend on physical and mental health, financial strength, companion, and education level. This study aimed to determine if the quality of life might be correlated with depressive symptoms. The ultimate goal was to help improve the quality of life and reduce the occurrence of depressive symptoms.

This study aims to make it maintained the life without inconvenience in daily life and to give a help to enhancement in the quality of life by grasping the relevance with mental health in the activity limitation and the quality of life in our country's adults. Through this, the aim is to offer basic data to a program of improving the quality of life.

\section{Materials and Methods}

\subsection{Research Tools}

This study was based on the source data of "Korea Health Statistics 2012: Korea National Health and Nutrition Examination Survey [KNHANES V-3]" by Ministry of Health and Welfare (MW) and Korea Centers for Disease Control and Prevention (CDC) ${ }^{8}$. The Korea National Health and Nutrition Examination Survey (KNHANES) is statutory research based on Article 16 of the National Health Promotion Law and produces government designated statistics based on Article 17 of the Statistics Act. It is also nationally approved statistics based on Article 18 of the Statistics Act. KNHANES was conducted at three-year intervals from the first (1988) to third sessions (2005). An annual research system has been applied since the fourth session (2007-2009). The respondents in the fifth session (2010-2012) were oneyear-old or older members of 3,800 households from 192 sampling districts and the survey was conducted between January and December. People in nursing homes, the army, and correctional institutions and foreigners were excluded from the population for KNHANES. KNHANES is largely divided into three categories: health, nutrition, and medical examination surveys. Of these, the health survey covers the quality of life, activity limitations, and mental health. This study used the quality of life, activity limitations, and mental health in the health survey from KNHANES.

The sphere of obtaining an analysis with the application in data of $\mathrm{MW}$ and $\mathrm{CDC}^{8}$ is the sphere of activity limitation and quality of life. In the sphere of activity limitation, adults were subjects. Thus, the age group in less than 20 years old was excluded. Also, in the sphere of activity limitation among people aged over 20, even the subjects with missing values were excluded from research subjects. In addition, the subjects who showed non-response were excluded as well.

The subjects of this study were totally 5515 people excluding 2543 people such as the subjects aged below 20 , the subjects with missing values, and non-respondents from totally 8058 people. Household income, education level, and occupation among the socio-demographic characteristics may lead to a difference in the number of persons less than 5515. There were missing subjects by household income, education level, and occupation but they were well checked by the other variables. So the subjects were selected in a missing state. Therefore, the difference less than 5515 in total was only found by such variables as household income, education level, and occupation.

The variables in this study were the socio-demographic characteristics, the quality of life, and mental health. Specifically, the socio-demographic characteristics included gender, age, household income, education level, occupation, and quality of life. The quality of life covered motor ability, self-management, daily activity, pain/discomfort, and anxiety/depression. Mental health involved depressive symptoms.

Among variables, the items for the socio-demographic characteristics and the mental health consisted of nominal/ ranking scales. The items for the quality of life (motor ability, self-management, daily activity, pain/discomfort, and anxiety/depression) were made of a 3-point Likert scale. The 3-point Likert scale implies that the lower score leads to the better quality of life and signifies that the higher score leads to the worse quality of life.

In the three-point Likert scale for the quality of life, self-management scored lowest with 1.05 on average, followed by daily activity with 1.10 , anxiety/depression 
with 1.14 , motor ability with 1.18 , and pain/discomfort with 1.26. The dependent variables in this study were "depressive symptoms". The independent variables were the "socio-demographic characteristics" and the "quality of life". In analyzing the results, the independent variables were converted into dummy variables to investigate "depressive symptoms" among dependent variables. The conversion was used to perform dichotomous logistic regression analysis.

\subsection{Analytical Method}

The analytical method of this study was made by using SPSS WIN 12.0 Version program. The dependent variables in analysis were "depressive symptoms". The independent variables were the socio-demographic characteristics and the quality of life. Specifically, $\chi^{2}$ was used to analyze the differences in "depressive symptoms" by the socio- demographic characteristics. Dichotomous logistic regression analysis was used to determine the effects of the socio-demographic characteristics on "depressive symptoms". $\chi^{2}$ was used to analyze the differences in "depressive symptoms" by the quality of life. Dichotomous logistic regression analysis was used to determine the effects of the quality of life on "depressive symptoms". The statistical significance level was set to be $\mathrm{p}<0.05$.

\section{Results}

\subsection{Experience of Depressive Symptoms by Socio-Demographic Characteristics}

The variation in the experience of depressive symptoms by the socio-demographic characteristics is presented in Table 1. Females (71.3\%) were more likely to have depressive symptoms for the past two weeks than males

Table 1. Experience of depressive symptoms by socio-demographic characteristics

\begin{tabular}{|c|c|c|c|c|c|}
\hline & & \multicolumn{2}{|c|}{$\begin{array}{c}\text { Depressive symptoms } \\
(5515) \\
\end{array}$} & \multirow[t]{2}{*}{$\chi^{2}$} & \multirow[t]{2}{*}{ p-value } \\
\hline & & Yes $(735)$ & No $(4780)$ & & \\
\hline \multirow{2}{*}{ Gender } & Male & $211(28.7)$ & $2069(43.3)$ & \multirow{2}{*}{55.820} & \multirow{2}{*}{$.000^{* * *}$} \\
\hline & Female & $524(71.3)$ & $2711(56.7)$ & & \\
\hline \multirow{5}{*}{ Age } & 20’s & $58(7.9)$ & $517(10.8)$ & \multirow{5}{*}{23.615} & \multirow{5}{*}{$.000^{* * *}$} \\
\hline & 30 's & $97(13.2)$ & $861(18.0)$ & & \\
\hline & 40 's & $120(16.3)$ & $837(17.5))$ & & \\
\hline & 50 's & $159(21.6)$ & $907(19.0)$ & & \\
\hline & 60 's $\leq$ & $301(41.0)$ & $1658(34.7)$ & & \\
\hline \multirow{4}{*}{ Household income ${ }^{\#}$} & Low & $193(26.8)$ & $821(17.3)$ & \multirow{4}{*}{42.873} & \multirow{4}{*}{$.000^{* * *}$} \\
\hline & Mid low & $194(26.9)$ & $1217(25.7)$ & & \\
\hline & Mid high & $161(22.3)$ & $1291(27.3)$ & & \\
\hline & High & $173(24.0)$ & $1403(29.6)$ & & \\
\hline \multirow{4}{*}{ Education level $^{\#}$} & Elementary school graduates & $251(34.2)$ & $1179(24.7)$ & \multirow{4}{*}{50.992} & \multirow{4}{*}{$.000^{* * *}$} \\
\hline & Junior high school graduates & $103(14.0)$ & $494(10.3)$ & & \\
\hline & High school graduates & $215(29.3)$ & $1595(33.4)$ & & \\
\hline & University graduates $\leq$ & $162(22.5)$ & $1511(31.6)$ & & \\
\hline \multirow{7}{*}{ Occupation ${ }^{\#}$} & Managers and professionals & $67(9.1)$ & $651(13.6)$ & \multirow[t]{3}{*}{41.053} & \\
\hline & Clerks & $46(6.3)$ & $404(8.5)$ & & \multirow{6}{*}{$.000^{* * *}$} \\
\hline & Sales and service workers & $89(12.1)$ & $553(11.6)$ & & \\
\hline & Agricultural and fishery workers & $60(8.2$ & $370(7.8)$ & & \\
\hline & Skilled workers & $37(5.0)$ & $445(9.3)$ & & \\
\hline & Manual workers & $70(9.5)$ & $425(8.9)$ & & \\
\hline & Unemployed (housewives and students) & $365(49.7)$ & $1926(40.3)$ & & \\
\hline \multirow{2}{*}{ Activity limitation } & Yes & $138(18.8)$ & $386(8.1)$ & \multirow{2}{*}{84.825} & \multirow{2}{*}{$.000^{* * *}$} \\
\hline & No & $597(81.2)$ & 4394(91.9) & & \\
\hline
\end{tabular}

p $\mathrm{p}<.001$ \# Household income, education level, and occupation got no response (missing) 
$(28.7 \%)(\mathrm{p}<.001)$. Those in their sixties or older $(41.0 \%)$ were most likely to be depressed $(\mathrm{p}<.001)$. The group with lower levels of household income (26.9\%) was more likely to have depressive symptoms $(\mathrm{p}<.001)$. Elementary school graduates $(34.2 \%)$ were more likely to have depressive symptoms $(\mathrm{p}<.001)$. The jobless $(49.7 \%)$ were more likely to have depressive symptoms $(\mathrm{p}<.001)$.

\subsection{Effects of Socio-Demographic} Characteristics on Depressive Symptoms Dichotomous logistic regression was used to analyze the effects of the socio-demographic characteristics on depressive symptoms. The dependent variables in this study were "depressive symptoms". Dichotomous logistic regression is used when dependent variables are dichotomous. The independent variable was converted into the dummy variable.

The results are presented in Table 2. Females were about 1.7 times more likely to have depressive symptoms than males $(\mathrm{p}<.001)$. The group with low levels of household income was more likely to have depressive symptoms than that with middle/high (approx. 1.5 times, $\mathrm{p}<.01$ ) or high levels of household income (approx. 1.5 times, $\mathrm{p}<.01$ ). The group with activity limitation was more likely to have depressive symptoms ( $\mathrm{p}<.001)$.

Table 2. Effects of socio-demographic characteristics on depressive symptoms

\begin{tabular}{|c|c|c|c|c|c|c|c|}
\hline & & \multirow[t]{2}{*}{ B } & \multirow[t]{2}{*}{ Wald } & \multirow{2}{*}{ Odds Ratio } & \multirow{2}{*}{$\mathrm{p}$} & \multicolumn{2}{|c|}{$\begin{array}{c}95 \% \text { Confidence } \\
\text { interval } \\
\end{array}$} \\
\hline & & & & & & lower & upper \\
\hline \multirow{2}{*}{ Gender $^{*}$} & Male & & & 1.00 & & & \\
\hline & Female & .511 & 28.617 & 1.667 & $.000^{* * *}$ & 1.382 & 2.009 \\
\hline \multirow{5}{*}{$\mathrm{Age}^{\#}$} & 20’s & & & 1.00 & & & \\
\hline & 30 's & -.058 & .104 & .994 & .747 & .666 & 1.338 \\
\hline & 40 's & -.254 & 2.173 & .776 & .140 & .554 & 1.087 \\
\hline & 50 's & -.249 & 2.002 & .779 & .157 & .552 & 1.101 \\
\hline & 60 's $\leq$ & -.003 & .000 & .997 & .998 & .698 & 1.426 \\
\hline \multirow{4}{*}{ Household income ${ }^{*}$} & Low & & & 1.00 & & & \\
\hline & Mid low & .266 & 5.011 & 1.305 & $.025^{*}$ & 1.034 & 1.646 \\
\hline & Mid high & .427 & 10.734 & 1.532 & $.001^{* * *}$ & 1.187 & 1.978 \\
\hline & High & .399 & 8.834 & 1.490 & $.003^{*}$ & 1.145 & 1.938 \\
\hline \multirow{4}{*}{ Education level ${ }^{\#}$} & Elementary school graduates & & & 1.00 & & & \\
\hline & Junior high school graduates & -.149 & 1.137 & .862 & .286 & .655 & 1.133 \\
\hline & High school graduates & .182 & 1.815 & 1.200 & .178 & .920 & 1.564 \\
\hline & University graduates $\leq$ & .309 & 3.642 & 1.361 & .056 & .992 & 1.869 \\
\hline \multirow{7}{*}{ Occupation $^{\#}$} & Managers and professionals & & & 1.00 & & & \\
\hline & Clerks & -.038 & .034 & .963 & .854 & .646 & 1.437 \\
\hline & Sales and service workers & -.116 & .394 & .891 & .530 & .620 & 1.279 \\
\hline & Agricultural and fishery workers & .006 & .001 & 1.006 & .976 & .663 & 1.527 \\
\hline & Skilled workers & .315 & 1.902 & 1.371 & .168 & .876 & 2.146 \\
\hline & Manual workers & -.027 & .017 & .974 & .895 & .655 & 1.446 \\
\hline & Unemployed (housewives and students) & -.119 & .560 & .888 & .454 & .649 & 1.213 \\
\hline \multirow{2}{*}{ Activity limitation ${ }^{*}$} & Yes & & & 1.00 & & & \\
\hline & No & -.781 & 46.612 & .458 & $.000^{+* *+}$ & .366 & .573 \\
\hline
\end{tabular}

${ }^{*} \mathrm{p}<.05,{ }^{* *} \mathrm{p}<.01,{ }^{* * * *} \mathrm{p}<.001$ \# Analysis after conversion into dummy variable 


\subsection{Experience of Depressive Symptoms by Quality of Life}

The variation in the experience of depressive symptoms by the quality of life is presented in Table 3 . The group having no problem with walking (69.7\%) in terms of motor ability was more likely to have depressive symptoms for the past two weeks $(\mathrm{p}<.001)$. The group capable of bathing and putting on clothes $(90.3 \%)$ in terms of self-management was more likely to have depressive symptoms $(\mathrm{p}<.001)$. The group having no problem with daily activity (79.7\%) was more likely to have depressive symptoms $(\mathrm{p}<.001)$. The group having no pain/discomfort (61.2\%) was more likely to have depressive symptoms $(\mathrm{p}<.001)$. The group having no anxiety/depression was more likely to have depressive symptoms $(\mathrm{p}<.001)$.

\subsection{Effects of Quality of Life on Depressive Symptoms}

The effects of the quality of life on depressive symptoms are presented in Table 4 . The group having some problems

Table 3. Experience of depressive symptoms by quality of life

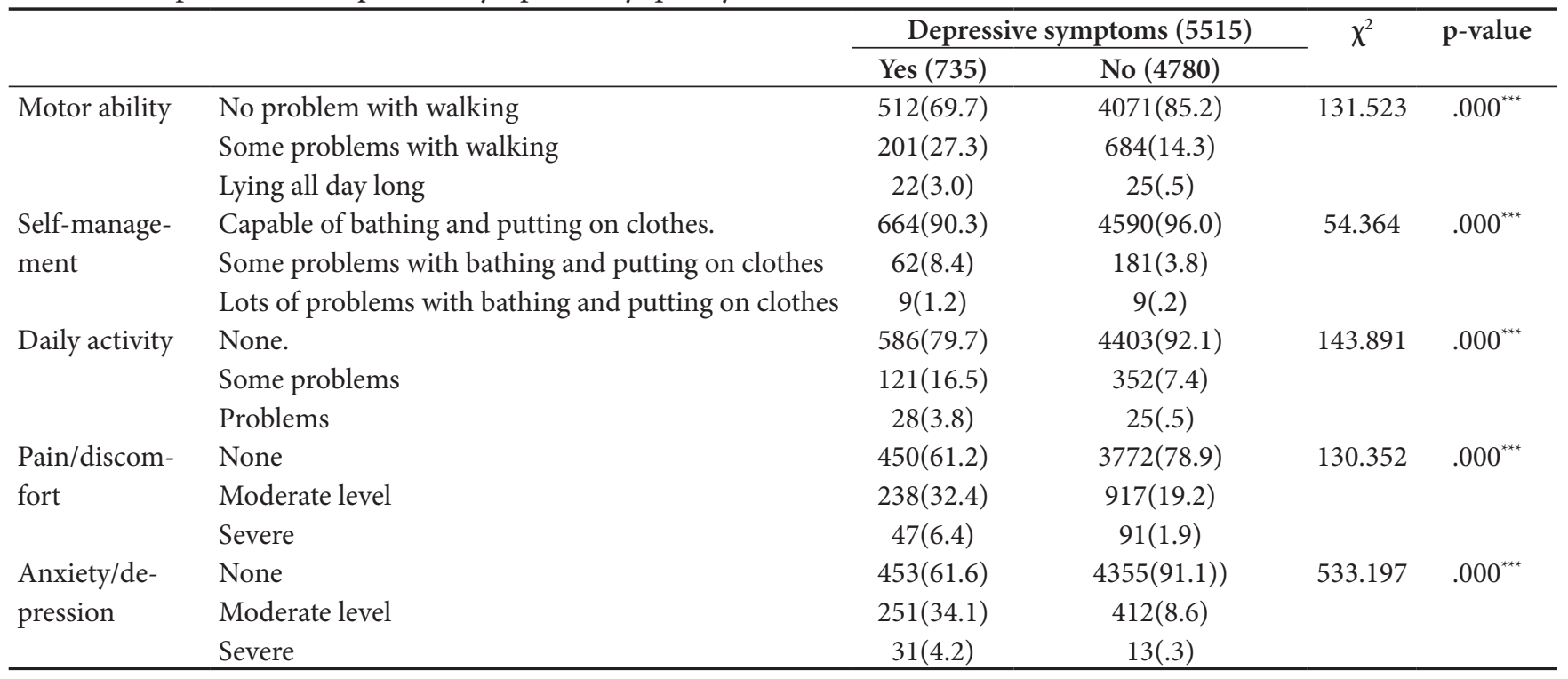

$\mathrm{p}<.001$

Table 4. Effects of quality of life on depressive symptoms

\begin{tabular}{|c|c|c|c|c|c|c|c|}
\hline & & \multirow[t]{2}{*}{ B } & \multirow[t]{2}{*}{ Wald } & \multirow{2}{*}{$\begin{array}{l}\text { Odds } \\
\text { Ratio }\end{array}$} & \multirow{2}{*}{$\mathrm{p}$} & \multicolumn{2}{|c|}{$\begin{array}{c}\text { 95\% Confidence } \\
\text { interval }\end{array}$} \\
\hline & & & & & & lower & upper \\
\hline \multirow{3}{*}{ Motor ability } & No problem with walking & & & 1 & .020 & & \\
\hline & Some problems with walking & .303 & 5.680 & 1.354 & $.017^{*}$ & 1.055 & 1.738 \\
\hline & Lying all day long & .782 & 3.742 & 2.187 & .053 & .990 & 4.831 \\
\hline \multirow{3}{*}{ Self-management } & Capable of bathing and putting on clothes. & & & 1 & .398 & & \\
\hline & Some problems with bathing and putting on clothes & -.271 & 1.839 & .763 & .175 & .516 & 1.128 \\
\hline & Lots of problems with bathing and putting on clothes & -.187 & 0.84 & .829 & .772 & .234 & 2.937 \\
\hline \multirow{3}{*}{ Daily activity } & None. & & & 1 & .082 & & \\
\hline & Some problems & .111 & .458 & 1.118 & .499 & .810 & 1.542 \\
\hline & Problems & .876 & 4.991 & 2.401 & $.025^{\star}$ & 1.113 & 5.178 \\
\hline \multirow{3}{*}{ Pain/discomfort } & None & & & 1 & .267 & & \\
\hline & Moderate level & .181 & 2.625 & 1.198 & .105 & .963 & 1.491 \\
\hline & Severe & .158 & .393 & 1.171 & .531 & .715 & 1.916 \\
\hline \multirow{3}{*}{ Anxiety/depression } & None & & & 1 & .000 & & \\
\hline & Moderate level & 1.613 & 253.309 & 5.017 & $.000^{* * *}$ & 4.113 & 6.119 \\
\hline & Severe & 2.621 & 53.353 & 13.756 & $.000^{* * *}$ & 6.808 & 27.795 \\
\hline
\end{tabular}

$\mathrm{p}<.05,{ }^{* * *} \mathrm{p}<.001$ 
with walking in terms of motor ability was about 1.4 times more likely to have depressive symptoms $(\mathrm{p}<.05)$. The group having problems with daily activity was about 2.4 times more likely to have depressive symptoms $(\mathrm{p}<.05)$. The group having moderate levels of psychological anxiety/depression (approx. 5 times, $\mathrm{p}<.001$ ) and the group having severe psychological anxiety/depression (approx. 1.4 times, $\mathrm{p}<.001$ ) were more likely to be depressed.

\section{Discussion}

This study aimed to determine the correlation between the quality of life and depressive symptoms. A decrease in motor ability, problems with daily activity, and psychological anxiety in terms of the quality of life were found to have a strong impact on depressive symptoms.

Han et al. ${ }^{7}$ noted that elderly people with physical disease were more likely to suffer depressive symptoms and disorders than normal ones. They also indicated that dysfunction caused by physical diseases had the greatest impact on the depressive symptoms. It is consistent with the result of this study that a decrease in motor ability and psychological anxiety had a strong impact on depressive symptoms. That is, physical and psychological changes may negatively affect human emotion, thereby causing depressive symptoms. Yu et al. ${ }^{9}$ noted that interaction between living stress and social support significantly affected psychological symptoms in general, depression, anxiety, and stress symptoms.

Cho and Yang $^{10}$ reported that post-traumatic negative belief and post-traumatic lack of social support might be significant predictors of post-traumatic stress symptoms. Despite the differences from this study in results and methods, it seems to mean that trauma can cause psychological problems. The similarity is that a decrease in motor ability, problems with daily activity and psychological anxiety can contribute to depressive symptoms.

Yoo $^{11}$ noted that spine injury might contribute to depression. $\mathrm{Kim}^{12}$ found that industrial disaster victims had a lower quality of life than normal people and were depressed. It is consistent with the result of this study that a decrease in motor ability contributed to depressive symptoms. That is, physical health is an important factor influencing depressive symptoms.

Kim et al. ${ }^{13}$, Cho et al. ${ }^{14}$, and Jeong and $\mathrm{Kim}^{15}$ noted that psychological anxiety affected psychological changes among both healthy and unhealthy people. Since psychological anxiety and depressive symptoms can be caused by physical and mental changes, it is necessary to change systems and awareness with the objective of improving the quality of life.

While there can be multiple variables that cause depressive symptoms, it is necessary to develop various systems with the aim of leading a comfortable and healthy life. To do this, it is necessary to reinforce a physical rehabilitation program both for people with decreased motor ability and for those having problems with daily activity. It is also necessary to reinforce a psychological rehabilitation program for people with great psychological anxiety. In addition, efforts should be made to develop institutional programs and to change personal awareness. It seems to be helpful in improving the quality of life to reinforce the foundation for personal and social support. Such reinforcement is expected to improve the physical and mental life.

In further research, various efforts should be made to improve the quality of life. These efforts are expected to provide basic data that can help develop a program to improve the quality of life.

This study has some limitations:

- With the missing subjects excluded, analysis was made with missing values present in some variables among the socio-demographic characteristics.

- The analysis was made in adults alone. It is therefore necessary to be careful in comparing the results of this study with those of other studies on the correlation between the quality of life and depressive symptoms.

\section{Conclusion}

This study aimed to determine the effects of the quality of life on depressive symptoms. Motor ability, problems with daily life and serious psychological anxiety may contribute to depressive symptoms. On the basis of these results, it is necessary to develop institutional programs to improve the quality of life and relieve psychological anxiety and to activate correct leisure activity policies.

\section{References}

1. Wade M. The harzards of immobility-effects on Psychological equilibrium. AJN. 1967; 67(4):794-5.

2. Heo JH, Cho YT. Activity limitations and health behaviors by socioeconomic status among the elderly seoul population. Journal of the Korean Gerontological Society. 2008; 28(1):87-104. 
3. Lee SD, Kim JG. The analysis of walking ability by the social environment, health condition and HRQoL based on the Korean National Health and Nutrition Examination Survey. Journal of the Korean Entertainment Industry Association. 2013; 8(2):83-93.

4. Hong JY, Kim EY, Jung JE, Park MS, Kang YA, Kim SG, Jang J, Kim YS. Factors associated with quality of life as measured by EQ-5D in patients with COPD. The Korean Academy of Tuberculosis and Respiratory Diseases. Autumn Conference. 2012; 114:202.

5. Park CK, Lee JR. Analysis of factors affecting the change of depression of korean adult male and female. J of Korean Association of Health and Medical Sociology. 2011; 29:99128.

6. Lee DH, Ham KA, Kim JY, Kim MK, Jung SW, Kim JB. Gender differences in DSM-IV major depression symptoms: Based on Korean Psychiatric Diagnostic Screening Questionnaire (K-PDSQ). Journal of Rehabilitation Psychology. 2013; 20(3):501-22.

7. Han JS, Lee HS, Lee SK, Jung IK. Depressive symptoms in elderly patients with physical illness. Journal of Korean Geriatirc Psychiatry. 1997; 1(1):100-11.

8. Korea Health Statistics 2012: Korea National Health and Nutrition Examination Survey, KNHANES v-3. Ministry of Health and Welfare (MW), Korea Centers for Disease Control and Prevention (CDC); 2013. Available from: http:// www.mw.go.kr

9. Yu YH, Lee SH, Cho YR. The relationships between self-compassion, life stress, social support, and psycholog- ical symptoms. J of Cognitive Behavior Therapy in Korea. 2010; 10(2):43-59.

10. Cho YR, Yang SS. Peri-traumatic dissociation, post-traumatic negative beliefs, and poor social support as predictors of long-term psychological symptoms following a natural disaster. Kor J Clin Psychol. 2013; 32(4):955-79.

11. Yoo YS. Study on factors affecting on the spinal cord injuries' depression-centering on the married man spinal cord injuries. The Korean Academy of Mental Health Social Work. 2001; 12:29-52.

12. Kim SI, Yun KW, Ha E, Woo HW, Kim YC. Quality of life, suicide ideation, and depressive symptoms in industrial injury patients. J of The Korean Neuropsychiatric Association. 2001; 40(3):416-24.

13. Kim KS, Yi MS, Bang KS, Cho YA, Lee JL, Lee E. Relationships among activity status, anxiety, depression, social support, symptom experience, and functional status in lung cancer patients based on the theory of unpleasant symptoms. Perspectives in Nursing Science. 2013; 10(2):87-96.

14. Cho YR, Noh SS, Jo KH, Hong SH. The effect of mindfulness-based intervention on depression and anxiety symptoms: A meta-analysis. Korean Journal of Psychology: General. 2014; 33(4):903-28.

15. Jeong HS, Kim OS. Anxiety, depression and health behavior of elderly with chronic diseases. J of Nursing Science. 2013; 25(2):35-46. 